\title{
Heat storage in upper and lower body during high-intensity exercise in athletes with spinal cord injuries
}

\author{
Robert C Pritchett (PhD) ${ }^{1}$ \\ James M Green (PhD, FACSM) ${ }^{3}$ \\ Kelly L Pritchett (PhD, RD, CSSD) ${ }^{1}$ \\ Phillip Bishop (PhD) ${ }^{2}$ \\ ${ }^{1}$ Department of Health, Human Performance and Nutrition, Central Washington University, Ellensburg \\ ${ }^{2}$ Department of Kinesiology, University of Alabama, Tuscaloosa \\ ${ }^{3}$ Department of Health, Physical Education and Recreation, University of North Alabama, Florence
}

\begin{abstract}
Background: The thermophysiology of athletes with spinal cord injuries $(\mathrm{SCl})$ is not well understood. Spinal cord lesions impact muscle mass, thermoregulatory neural signals and circulatory function. Understanding $\mathrm{SCl}$ thermoregulation physiology would benefit exercise function. Therefore, this study was designed to describe heat storage in the upper and lower bodies of $\mathrm{SCl}$ and able-bodied (AB) athletes.

Procedure: Seven $\mathrm{SCl}$ and $8 \mathrm{AB}$ athletes (matched for armcrank $\mathrm{VO}_{2}$ peak) performed a ramp protocol in an environment similar to an indoor competitive environment $\left(21^{\circ} \mathrm{C} \pm 1.5^{\circ} \mathrm{C}, 55 \pm 3 \%\right.$ relative humidity).

Results: $\mathrm{SCl}$ athletes experienced similar upper-body heat storage of $0.82 \pm 0.59 \mathrm{~J} \mathrm{~g}^{-1}$ and lower-body heat storage of $0.47 \pm 0.33$ $\mathrm{J.g}^{-1}$ compared with that of $A B$ athletes at $0.80 \pm 0.61 \mathrm{~J}^{-1}$ and $0.27 \pm 0.22 \mathrm{J.g}^{-1}$ for upper and lower body, respectively. There were no significant differences between groups for rectal temperature $\left(T_{\text {rec }}\right)$ or oesophageal temperature $\left(T_{e s}\right)$. However, mean skin temperature $\left(\mathrm{M}_{\mathrm{sk}}\right)$ was significantly higher for $\mathrm{SCl}$ throughout the exercise bout $(p=0.006)$.

Conclusions: The results of this study suggest that $\mathrm{SCl}$ and $\mathrm{AB}$ athletes appear to thermoregulate in a similar manner, though $\mathrm{SCl}$ tend to store slightly more heat.
\end{abstract}

\section{Introduction}

Research on heat storage differences between the upper body and lower body for paraplegic athletes is sparse. However, a few stud-

\section{CORRESPONDENCE:}

\section{R C Pritchett}

Department Health Human Performance and Nutrition

Central Washington University

400 East University Way

Ellensburg, WA, 98926

Tel: $509-963-1338$

Fax: 509-963-1848

E-mail: pritcher@cwu.edu ies have reported heat storage when evaluating the effectiveness of various cooling interventions. Webborn et al. ${ }^{1}$ examined the effects of two cooling strategies (pre-cooling and cooling during exercise) on thermoregulatory responses of tetraplegic athletes. The authors, using a repeated measures design, examined two strategies during 28 minutes of intermittent arm crank exercise. The authors reported no difference $(p=0.39)$ in heat storage between a control trial $(3.62 \pm 0.4$ $\left.\mathrm{J.g}^{-1}\right)$ and either intervention during pre-cooling $\left(4.17 \pm 0.4 \mathrm{~J} . \mathrm{g}^{-1}\right)$ and cooling during exercise $\left(3.15 \pm 0.35 \mathrm{J.g}^{-1}\right)$.

Price and Campbell ${ }^{2}$ examined upper- v. lower-body skin temperature in paraplegic athletes. Results from arm ergometry exercise indicated that paraplegic athletes ( $\mathrm{v}$. able-bodied athletes), showed lower skin temperatures for the lower body after 90 minutes of work at $80 \%$ of peak heart rate $(\mathrm{HR})$ in room temperature. However, upper-body skin temperature was also lower for the paraplegic group v. the able-bodied group. The authors speculated that this could be due to atrophied musculature and/or an atrophied vascular system below the level of lesion. ${ }^{2}$ Unfortunately no information was provided on rectal or oesophageal temperatures (two accepted measures of core body temperature), so heat storage cannot be calculated for the upper-body and lower-body regions. Furthermore, no effort was made to match groups for fitness.

In general, paraplegics seem to adequately regulate body core temperature at rest; however, they show a greater increase in core temperature when compared with able-bodied $(A B)$ subjects during exercise and/or working conditions work. ${ }^{3}$ Furthermore, it has been demonstrated that individuals with a T6 (thoracic) lesion and below are subjected to smaller increases in core temperature than those individuals with a lesion above T6. These individuals, in turn, demonstrate smaller increases than those with tetraplegia (cervical lesions). ${ }^{4}$ Individuals with a spinal cord injury at or above T6 are prone to episodes of autonomic hyperreflexia when exposed to incompensable stimuli. These responses have been well documented by Jacobs and Nash, ${ }^{5}$ who further suggest that a common stimulus amongst others is a sudden rise in core temperature.

There seems to be a lack of knowledge regarding heat storage differences between upper-body ( $\mathrm{HS}_{\text {upper}}$ ) and lower-body ( $\mathrm{HS}_{\text {lower }}$ ) regions over the period of an exercise bout, particularly in spinal cord injured athletes $(\mathrm{SCl})$ athletes. Understanding the heat storage of $\mathrm{SCl}$ athletes will illuminate both the thermal physiology as well as the circulatory function of this group. Furthermore, enhancing the knowledge of thermal physiology within this cohort could aid in the development of more effective cooling interventions. For example, 
the lower skin temperatures in $\mathrm{SCl}$ participants reported by Price et al. ${ }^{6}$ may reflect a higher core temperature and reduced cutaneous vasodilatation, suggesting less effectiveness of skin cooling. A reduction in skin cooling has recently been noted by Pritchett et al., ${ }^{7}$ where the authors highlighted a decrease in sweat response among participants with $\mathrm{SCl}$, which led to a decreased ability to thermoregulate. This study therefore proposes to describe the heat storage dynamics over the course of a 235 -minute graded exercise bout under simulated gymnasium playing conditions $\left(20^{\circ} \mathrm{C} \pm 1^{\circ} \mathrm{C} ; 45-\right.$ $65 \pm 0.1 \%$ relative humidity) in both $\mathrm{SCl}$ and $\mathrm{AB}$ participants.

\section{Method}

\section{Participants}

Fifteen volunteers gave their informed consent to participate in this investigation, which had received approval by the University of Alabama Institutional Review Committee. The group was comprised of 7 paraplegic athletes $(\mathrm{SCl})$ and $8 \mathrm{AB}$ upper-body trained athletes (see Table I).

$A B$ athletes were wheelchair basketball team members absent of $\mathrm{SCl}(N=4)$, and the remainder $(N=4)$ were from the university swimming team.

Based on an alpha level of 0.05 an effect size of 1.0, a SD of $0.5 \mathrm{Jxg}^{-1}$ for heat storage, and a power of 0.80 , an a priori power analysis indicated 7 subjects would be needed. ${ }^{8}$

\section{Exercise tests}

Participants visited the laboratory on two separate occasions. On the first occasion, volunteers performed an incremental arm-crank exercise (ACE) test to determine $\mathrm{VO}_{2}$ peak with gas exchange indices collected using a Vacumed Vista mini cpx metabolic measurement system (Vacumed, Vista, CA). This involved two 5-minute submaximal exercise stages of arm-crank exercise ( $30 \mathrm{~W}$ and $50 \mathrm{~W}$ ) separated by 1 minute of passive recovery. ${ }^{9}$ Once the two submaxi- mal ACE stages and a rest stage had been completed, volunteers exercised to volitional exhaustion at a ramp rate of $20 \mathrm{~W}$ every 2 minutes from an initial level of $110 \mathrm{~W}$. All tests were conducted on a cycle ergometer (Monark 850E, Varberg, Sweden) adapted for upper-body exercise. Participants were instructed to maintain at least 50 rev. $\min ^{-1}$ throughout the test. For the second laboratory visit the exercise test consisted of multiple stages, beginning at a workload of $35 \mathrm{~W}$. Resistance of each stage was held constant for 7 minutes. At the end of each stage, participants had a 1-minute passive recovery. The workload of each stage increased by $35 \mathrm{~W}$, until such time that heat production exceeded heat dissipation as evidenced by a sudden increase in the time-slope of the $T_{\text {es }}$. The increase in $T_{\text {es }}$ was identified as critical when it was greater than $0.2^{\circ} \mathrm{C}^{-1}$ per minute. ${ }^{10}$ Temperature measures were conducted during the second laboratory visit only.

\section{Temperature measures}

On arrival at the laboratory for the incremental test, thermocouples (Physitemp Instruments INC., Clifton, NJ, USA) were positioned for measurement of rectal $\left(T_{\text {rec }}\right)$ and oesophageal temperatures $\left(T_{e s}\right)$. The oesophageal thermocouple was inserted with the following procedure. The inside of the nose of the subject was swabbed with a mild anaesthetic jelly (7.5\% Benzocaine), and a light covering of jelly was also placed on the distal end of the thermistor. A single spray of a topical anaesthetic (Cetacaine, 14\% Benzocaine, Cetylite Ind., Pennsauken, NJ USA) was sprayed on the back of the throat. After 2 minutes, the volunteers advanced the oesophageal probe through the nose and to the pharynx. At this point the probe was withdrawn slightly, and the volunteer was then requested to drink water through a right-angle straw and at the same time the probe was advanced into the oesophagus to a length of one-fourth of the volunteer's supine height and then taped to the nose and across the shoulder. ${ }^{11}$ A flexible rectal thermocouple $\left(T_{\text {rec }}\right)$ probe was self-inserted $\sim 8 \mathrm{~cm}$ beyond the anal sphincter. The rectal probe was securely taped, and

TABLE I. Anthropometric and physiological measurements (means \pm SD) for able-bodied (AB) and spinal cord injured (SCl) participants (level of lesion and completeness of injury presented for $\mathrm{SCl}$ )

\begin{tabular}{|c|c|c|c|c|c|c|c|c|c|c|c|c|}
\hline \multicolumn{7}{|c|}{$\mathrm{SCl}(N=7)$} & \multicolumn{6}{|c|}{$A B(N=8)$} \\
\hline Subject & Age & $\begin{array}{l}\text { Height } \\
\text { (cm) }\end{array}$ & $\begin{array}{l}\text { Weight } \\
(\mathrm{kg})\end{array}$ & $\begin{array}{l}\text { Injury } \\
\text { level }\end{array}$ & $\begin{array}{l}\mathrm{VO}_{2} \\
\text { peak } \\
\text { I.min }^{-1}\end{array}$ & $\begin{array}{l}\text { Body fat } \\
(\%)\end{array}$ & Subject & Age & $\begin{array}{l}\text { Height } \\
\text { (cm) }\end{array}$ & $\begin{array}{l}\text { Weight } \\
(\mathrm{kg})\end{array}$ & $\begin{array}{l}\mathrm{VO}_{2} \\
\text { peak } \\
\text { I.min }\end{array}$ & $\begin{array}{l}\text { Body fat } \\
(\%)\end{array}$ \\
\hline 1 & 23 & 170 & 60.0 & $\mathrm{~T} 12 / \mathrm{L} 1$ & 2.06 & 25 & 1 & 21 & 185 & 73.0 & 3.20 & 14 \\
\hline 2 & 31 & 174 & 44.5 & $\begin{array}{l}\text { T5 Com- } \\
\text { plete }\end{array}$ & 2.02 & 36 & 2 & 29 & 179 & 77.0 & 2.90 & 12 \\
\hline 3 & 23 & 189 & 65.8 & $\begin{array}{l}\text { T11 } \\
\text { Complete }\end{array}$ & 2.89 & 10 & 3 & 23 & 198 & 93.0 & 4.10 & 16 \\
\hline 4 & 19 & 174 & 57.0 & $\begin{array}{l}\text { T12 } \\
\text { Complete }\end{array}$ & 1.95 & 12 & 4 & 28 & 165 & 70.0 & 2.38 & 23 \\
\hline 5 & 26 & 172 & 54.4 & $\begin{array}{l}\text { T6 In- } \\
\text { complete }\end{array}$ & 2.93 & 13 & 5 & 23 & 152 & 69.0 & 1.98 & 32 \\
\hline 6 & 20 & 157 & 44.4 & $\begin{array}{l}\text { T3 Com- } \\
\text { plete }\end{array}$ & 1.81 & 18 & 6 & 38 & 155 & 64.0 & 2.04 & 20 \\
\hline \multirow[t]{2}{*}{7} & 26 & 176 & 51.0 & $\begin{array}{l}\text { T11 } \\
\text { Complete }\end{array}$ & 2.60 & 27 & 7 & 24 & 160 & 66.0 & 2.50 & 25 \\
\hline & & & & & & & 8 & 38 & 153 & 48.0 & 1.90 & 13 \\
\hline Mean \pm & 24 & 173 & $53.9^{*}$ & & 2.3 & 20 & & 28 & 168 & 70.0 & 2.60 & 19 \\
\hline SD & 4 & 9 & 7.9 & & 0.5 & 10 & & 7 & 17 & 12.7 & 0.80 & 7 \\
\hline
\end{tabular}


the thermocouple wire was passed over the back of the wheelchair to minimise interference with arm cranking.

Skin temperature $\left(T_{\text {sk }}\right)$ was continuously monitored from thermocouples placed at the following sites: forehead, forearm, upper arm, back, chest, thigh and calf. Thermocouples were attached to the skin using adhesive tape, cut around the head of the thermocouple, which held thermocouples in place without adding insulation.

Heat storage was calculated from the formula by Havenith et al. ${ }^{12}$ Heat storage for the upper-body region was calculated using $\Delta \mathrm{T}_{\text {es }}$ and $\Delta \mathrm{T}_{\text {sk }}$ by tabulating the weighted mean skin temperature between forearm $(20 \%)$, back $(40 \%)$ and chest $(40 \%)$. Lower-body heat storage was calculated using $\Delta \mathrm{T}_{\text {rec }}$ and $\Delta \mathrm{T}_{\mathrm{sk}}$, which was calculated using the mean skin temperature (thigh $70 \%$ and calf $30 \%$ ) from the formula of Ramanathan. ${ }^{13}$ Heat storage for each region was calculated where:

Heat storage $=\left(0.8 \Delta \mathrm{T}_{\text {rec }}\right.$ or $\left.\mathrm{T}_{\text {es }}+0.2 \Delta \mathrm{T}_{\text {skin }}\right) \times \mathrm{C}_{\mathrm{b}}$, where $\mathrm{C}_{\mathrm{b}}$ is the specific heat capacity of body tissue (3.49 $\mathrm{x} \mathrm{g}^{-1} \mathrm{x}^{\circ} \mathrm{C}^{-1}$ ).

\section{Statistical analysis}

Heat storage for the upper body ( $\mathrm{HS}_{\text {upper}}$ ) and heat storage for the lower body ( $\mathrm{HS}_{\text {lower }}$ ) were compared using paired $t$-tests. Level of significance was set at alpha $\leq 0.05$. A one-way analysis of variance was used to compare the difference between $\mathrm{SCl}$ athletes and matched $A B$ athletes. Furthermore, to allow for a depletion of subjects due to differentiated termination time, a harmonic mean was calculated and analysis over time using a repeated measures ANOVA with a Bonferroni post hoc test employed where necessary.

\section{Results}

Descriptive statistics (means and standard deviations) for $\mathrm{SCl}$ and $A B$ are presented in Table I. There was no difference in absolute $\mathrm{VO}_{2}$ peak, stature and age. However, body mass was significantly different between groups $(p=0.03)$. AB athletes were matched to $S C l$ athletes based on activity status, $\mathrm{VO}_{2}$ peak, with 3 of the $8 \mathrm{AB}$ being active participants in college wheelchair basketball. Thermoregulatory responses during exercise for $\mathrm{SCl}$ and $\mathrm{AB}$ were compared and presented graphically. There was no significant difference $(p=0.06)$ in $\mathrm{T}_{\text {es }}$ between $\mathrm{SCl}\left(38.0 \pm 0.2^{\circ} \mathrm{C}\right)$ and $\mathrm{AB}\left(37.6 \pm 0.4^{\circ} \mathrm{C}\right)$ (Fig. 1). Howev$\mathrm{er}$, it was noted that there was a greater increase in $\mathrm{T}_{\mathrm{es}}$ for $\mathrm{SCl}$ within the last two stages of the exercise bout. $T_{\text {rec }}$ (Fig. 2) for both groups were similar with no statistical difference between groups $(p>0.05)$. Figures are reported with the sample size, as the increasing intensity lead to a depleted sample size as individual termination points were reached. One subject (T3 lesion level) completed two stages, and was matched with an $A B$ subject that completed two stages. Only two subjects could not complete the final stage $(90 \mathrm{~W})$. Data are presented for all stages that more than $70 \%$ of the subjects completed. Analysis of variance indicated that mean skin temperature for the lower body $\left(\mathrm{M}_{\mathrm{sk}}\right)$ (Fig. 4) for $\mathrm{SCl}$ subjects was significantly higher than for $A B$ throughout the exercise bout $(p=0.006)$. However, mean skin temperature for the upper body (Fig. 3 ) was significantly different than for the first $(30 \mathrm{~W})$ stage $\left(\mathrm{SCl}: 35.2 \pm 0.9^{\circ} \mathrm{C}, \mathrm{AB}: 33.4 \pm 0.8^{\circ} \mathrm{C}\right)$ and second stage $(50 \mathrm{~W})\left(\mathrm{SCl}: 33.4 \pm 0.9^{\circ} \mathrm{C}, \mathrm{AB}: 33.7 \pm 1.0^{\circ} \mathrm{C}\right)$. However, for the last two stages, there were no significant differences detected between groups. There was no significant difference observed between upper body and lower body for heat storage between $\mathrm{SCl}$ and AB athletes ( $p=0.38$, Fig. 5). Furthermore, it is interesting to note that there was a significant difference observed between $\mathrm{HS}_{\text {upper }}$ and $\mathrm{HS}_{\text {lower }}$ body for SCl $\left(0.82 \pm 0.59 \mathrm{J.g}^{-1}\right.$ and $\left.0.47 \pm 0.33 \mathrm{J.g}^{-1}\right)(p=0.04)$ and also for $A B\left(0.80 \pm 0.61 \mathrm{~J}^{-1}\right.$ and $\left.0.27 \pm 0.22 \mathrm{~J}^{-1} \mathrm{~g}^{-1}\right)(p=0.03)$. Heat storage for $\mathrm{SCl}$ and $\mathrm{AB}$ per stage for both upper and lower body are

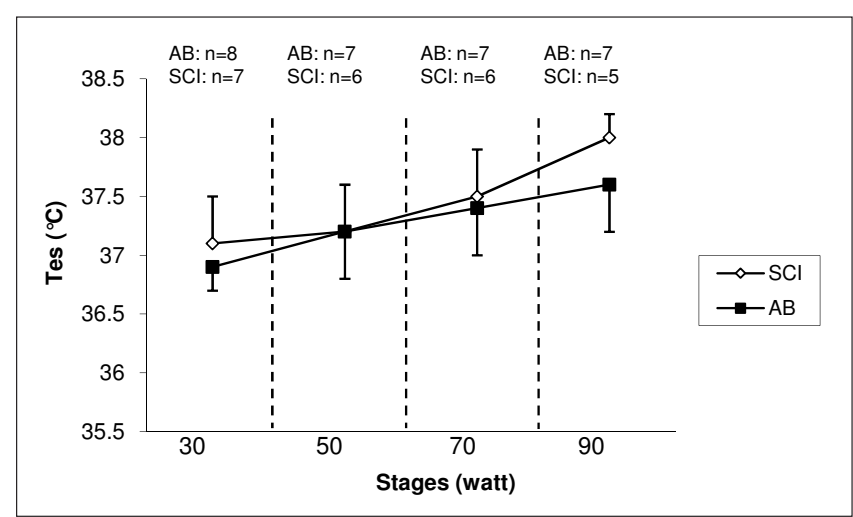

Fig. 1. Oesophageal temperature ( $T_{\mathrm{es}}$ ) for $\mathrm{SCl}$ and $A B$ athletes during incremental exercise for arm-crank ergometry. Sample size (N) is given for each stage that was completed.

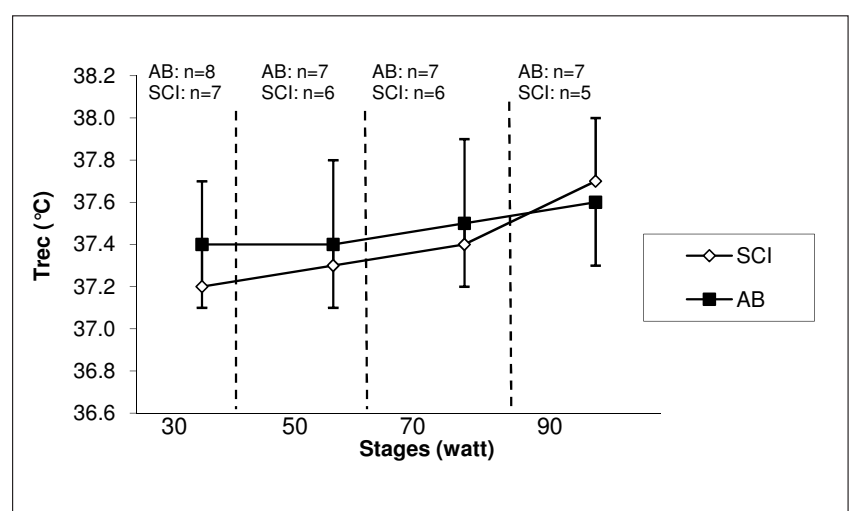

Fig. 2. Rectal temperature $\left(T_{\text {rec}}\right)$ for $\mathrm{SCl}$ wheelchair athletes and $A B$ controls during incremental exercise for arm-crank ergometry. Sample size (N) is given for each stage that was accomplished.

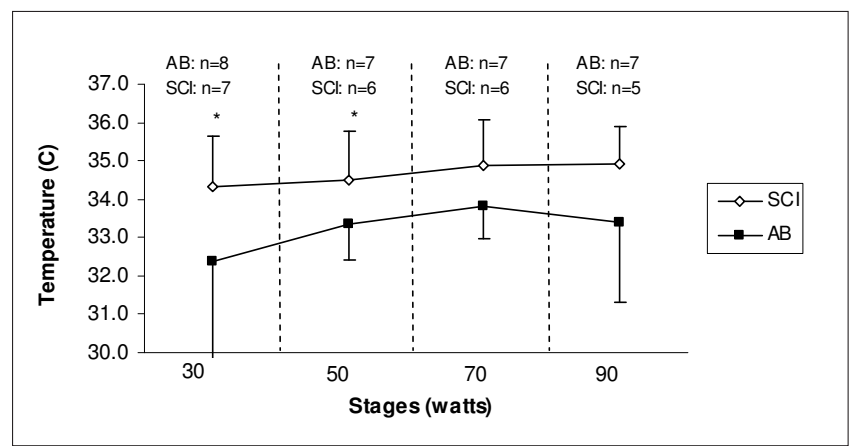

Fig. 3. Upper body mean skin temperatures ( $M_{\text {sk-upper }}$ ) for $S C l$ wheelchair athletes and $A B$ controls during incremental exercise for arm-crank ergometry. Sample size (N) is given for each stage that was accomplished.

presented in Figs $6 \mathrm{~A}$ and B, respectively. There was no significant difference for $\mathrm{HS}$ between stages for either group.

\section{Discussion}

The current study was undertaken in a common mild environment (simulation of a typical wheelchair basketball playing environment) under exercise conditions that were intended to simulate the duration and intensity of a typical competition half. Our intent was to maintain high ecological validity throughout the investigation in order to make the results of this study inferable to an active $\mathrm{SCl}$ population par- 


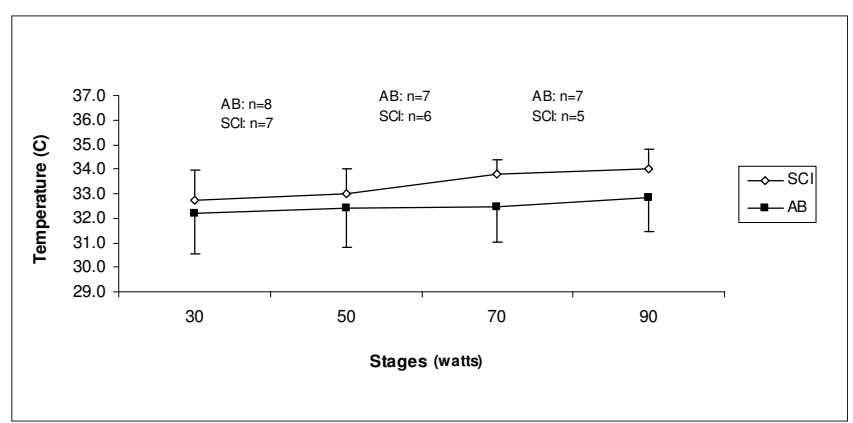

Fig. 4. Lower body mean skin temperature ( $M_{\text {sk-lower) for } \mathrm{SCI}}$ wheelchair athletes and $A B$ controls during incremental exercise for arm-crank ergometry. Sample size (N) is given for each stage that was accomplished.

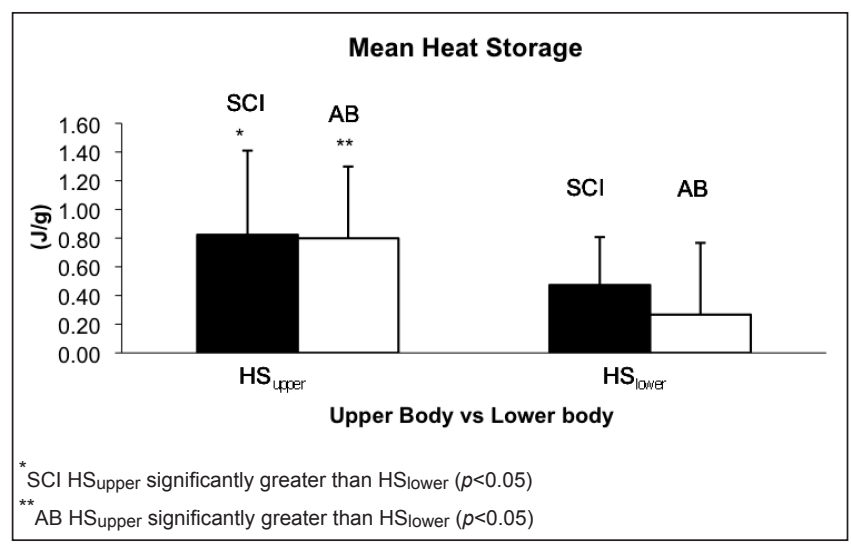

Fig. 5. Mean heat storage for $\mathrm{SCl}$ wheelchair athletes and $A B$ controls during incremental exercise for arm-crank ergometry.

taking in wheelchair sports. It has been stated that individuals with $\mathrm{SCl}$ have a compromised ability to thermoregulate, which can lead to magnified risk of thermal injury. ${ }^{14}$ The purpose of this paper was to add to the understanding of the thermophysiology of heat storage in $\mathrm{SCl}$ athletes.

All subjects were matched based on fitness. Three $A B$ subjects had experienced training identical to the $\mathrm{SCl}$ group participating on the same wheelchair basketball team and swimming teams (absolute $\mathrm{VO}_{2}$ peak is presented in Table I). Buresh et al. ${ }^{15}$ suggested body mass and heat storage in $A B$ athletes are significantly correlated. However, it is difficult to match these two populations ( $\mathrm{SCl}$ and $\mathrm{AB}$ ) for body mass.

As heat storage is a composite of both core temperature and skin temperature changes, for this study heat storage was compared between upper and lower body. There were lower heat storage values for the lower body compared with the upper body for both groups. However, there was no significant difference between groups. Reduced heat storage for the lower body might have been due to the lack of muscular contraction in the lower body. Therefore, there was little metabolic heat production. $\mathrm{HS}_{\text {lower }}$ was comprised of $\mathrm{T}_{\text {rec }}$ and $M_{\text {sk }}$ (calf and thigh). There was no significant difference in the change in $\mathrm{T}_{\text {rec }}$ between the $\mathrm{SCl}$ and $\mathrm{AB}$ groups. This could account for little differences detected between the two populations. Both groups also demonstrated little difference for $\mathrm{HS}_{\text {upper. }}$. Greater HS for the upper body observed for both groups might have been due to the nature of the exercise mode. It could also be speculated that due to the SCI athletes having a greater sweat response above their level of lesion. It has been demonstrated that at rest $\mathrm{SCl}$ athletes have warmer skin temperature, which enables an earlier onset of sweating, and

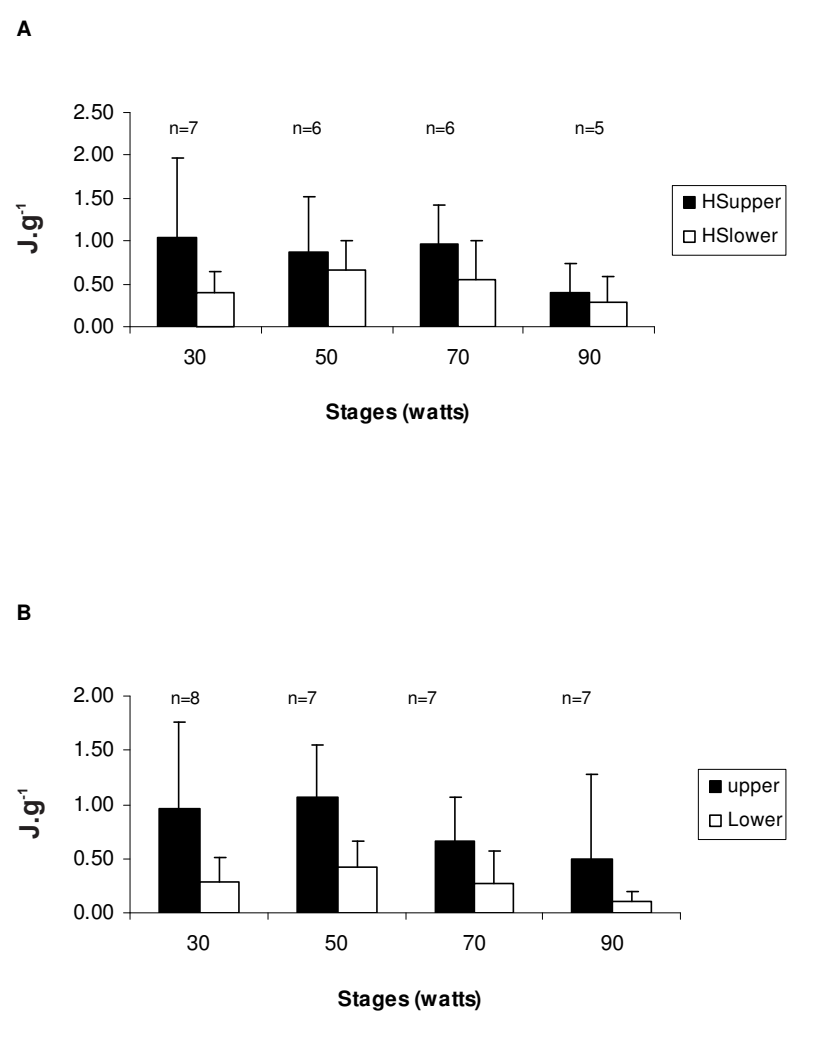

Fig. 6. Heat storage per stage for $\mathrm{SCl}$ wheelchair athletes (A) and $A B$ controls (B) during incremental exercise for arm-crank ergometry. Sample size $(\mathrm{N})$ of athletes that completed the stage.

therefore earlier skin cooling when compared with $A B$ athletes. ${ }^{16}$ This upper-body adaptation to an impaired thermoregulatory ability might help compensate for the lower body inability to dissipate stored heat.

$\mathrm{M}_{\text {sk }}$ temperature (Fig. 3) for the upper body was higher than the lower-body skin temperature in $\mathrm{SCl}$. Also, $\mathrm{SCl}$ experienced higher mean skin temperature in both the upper and lower body than did the AB. This is in accordance with Fitzgerald et al., ${ }^{17}$ who noted that volunteers with $\mathrm{SCl}$ who performed prolonged exercise at $24-25^{\circ} \mathrm{C}$ experienced an increase of $\sim 0.7^{\circ} \mathrm{C}$ (in core temperature). It was suggested that the increase in $M_{s k}$ was due to heat being generated from the working muscles, which was then transferred to the skin. Heat from the insensate skin would not be able to be dissipated, thus this would result in an increase in skin temperature.

One of the more extensively compiled research composites is that of sweat response between $\mathrm{AB}$ and $\mathrm{SCl}$ individuals and between different levels of $\mathrm{SCl}^{3,4,18}$ A reduction in whole-body sweating leads to greater increase in core temperature at rest, and a greater drive for sweating for a given environmental temperature. ${ }^{19,20}$ The current investigation reported slightly elevated $\mathrm{T}_{\mathrm{es}}$ for $\mathrm{SCl}$ athletes initially $\left(37.1 \pm 0.4^{\circ} \mathrm{C}\right)$ compared with $\mathrm{AB}\left(36.9 \pm 0.2^{\circ} \mathrm{C}\right)$. Similar responses were recorded for $\mathrm{T}_{\text {rec }}\left(\mathrm{SCl}=37.2 \pm 0.5^{\circ} \mathrm{C}\right.$ and $\left.\mathrm{AB}=37.4 \pm 0.3^{\circ} \mathrm{C}\right)$. However, it could be noted that the fluctuation in $T_{\text {es }}$ and $T_{\text {rec }}$ could quite possibly be due to circadian variation or day-to-day variations. Trec was late to increase in the $\mathrm{SCl}$ athletes, only showing increase in the last two stages. This could possibly be due to a lag time experienced in Trec measures, where rectal temperature measures have been shown to respond more slowly. ${ }^{11}$ 


\section{Conclusion}

In summary, the current study examined the heat storage response during upper-body high-intensity exercise. Results of this study suggest $\mathrm{SCl}$ and $\mathrm{AB}$ athletes were similar with respect to thermoregulation during arm cranking. $\mathrm{SCl}$ athletes tended to store slightly more heat in the lower body than $A B$ athletes. Both groups also demonstrated little difference for heat storage in the upper body. Similarly, there was no significant difference observed for lower-body heat storage values. In a simulated gymnasium temperature environment it appears the matched groups demonstrated few meaningful differences in the current paradigm. Future research should look at more sophisticated observation of heat transfer like thermography to better understand the dynamics of stored heat within this population during high-intensity activity.

\section{References}

1. Webborn N, Price MJ, Castle PC, Goosey-Tolfrey VL. Effects of two cooling strategies on thermoregulatory responses of tetraplegic athletes during repeated intermittent exercise in the heat. J Appl Phyiol 2005;98:2101-2107.

2. Price MJ, Campbell IG. Thermoregulatory responses of paraplegic and able-bodied athletes at rest, during exercise and into recovery. Eur J App Physiol 1997;76:552-560.

3. Price MJ. Thermoregulation during exercise in individuals with spinal cord injuries. Sports Med 2006;36(10):863-879.

4. Guttman WL, Silver J, Wyndham $\mathrm{CH}$. Thermoregulation in spinal man. J Physiol 1958;142:406-419.

5. Jacobs PL, Nash MS. Exercise recommendations for individuals with spinal cord injury. Sports Med 2004;34(11):727-751.

6. Price MJ, Campbell IG. Thermoregulatory and physiological responses of wheelchair athletes to prolonged arm crank ergometry. Inter J Sports Med, 1999;20:457-463.
7. Pritchett RC, Bishop PA, Green JM, Richardson M, Zhang Y, Kerr KL. Evaluation of artificial sweat in athletes with spinal cord injuries. Eur $J$ Appl Physiol 2010;109(1):125-131.

8. Lenth RV. Java applets for power and sample size [computer software] http://www.stat.uiowa.edu/ rlenth/Power (accessed 17 November 2006)

9. Price MJ, Campbell IG. Thermoregulatory responses of able bodied, upper body trained athletes to prolonged arm crank exercise in cool and hot conditions. J Sports Sci 2002;20:519-527.

10. O'Conner DJ, Barnard TE. Continuing the search for WBGT clothing adjustment factors. Appl Occ Env Hygiene 1999;14:119-125.

11. Gass GC, Camp EN, Nadel ER, et al. Rectal and rectal vs. esophageal temperatures in paraplegic men during prolonged exercise. J Appl Physiol 1988;64(6):2265-2271.

12. Havenith G, Inoue $\mathrm{Y}$, Luttikholg B, et al. Age predicts cardiovascular, but not thermoregulatory, responses to humid heat stress. Eur J Appl Physiol 1995; $70: 88-96$

13. Ramanathan NL. A new weightings system for mean surface temperature of the human body. J Appl Physiol 1964;19:531-533.

14. Bhambhan, Y. Physiology of wheelchair racing in athletes with spinal cord injury. Sports Med 2002:32:23-51.

15. Buresh R, Berg D, Noble J. Heat production and storage are positively correlated with measures of body size/composition and heart rate drift during vigorous running. Res Quart Exerc Sport 2005;76(3):267-275.

16. Van Beaumont, Bullard RW. Sweating: Its rapid response to muscular work. Sci 1963:141:643-646.

17. Fitzgerald PI, Sedlock DA, Knowlton RG. Circulatory and thermal adjustments to prolonged exercise in paraplegic women. Med Sci Sports Exerc 1990;22:629-635.

18. Hopman MTE, van Asten WN, Oesburg B. Blood flow changes below and above the spinal cord lesion during arm exercise in individuals with paraplegia. Eur J Appl Physiol 1994:69;S26.

19. Huckaba CE, Frewin DB, Downey JA, Tam, H-S, Darling, RC, Cheh HY. Sweating responses of normal, paraplegic and anhidrotic subjects. Arch Phys Med Rehab 1976;57:268-274.

20. Tam HS, Darling RC, Cheh HY, Downey, AJ. Sweating response: A means of evaluating a set-point theory during exercise. J Appl Physiol 1978;45(3):451-458. 